\title{
As Temáticas e Abordagens dos Poemas do MANYÔSHÛ
}

Geny Wakisaka

A antologia poética japonesa Manyôshû, organizada provavelmente na segunda metade do séc. VIII, insere 4560 poemas distribuidos em seus 20 volumes. Este número de poemas porém, varia conforme cópias elaboradas no decorrer dos anos, através das quais ela é hoje conhecida.

A obra em questão registra produçōes poéticas de variadas formas e temáticas, nos desvendando um acervo poético valoroso, trabalhos de todas as camadas sociais do Japão de então, onde desfilam lado a lado poetas imperadores, nobres ou populares anônimos.

O mais antigo poema nela inserido é de autoria de Iwahime, segundo nota, esposa do lendário imperador Nintoku, que presumivelmente viveu no início do séc. IV e o mais recente, datado de 1 de janeiro de 759, pertence ao poeta Otomono Yakamochi, apontado como um dos organizadores dessa antologia.

O Manyôshû registra pois, a produção poética de quase quatro séculos, apesar de suas produçōes estarem concentradas nos 150 anos finais) do povo japonês.

Os poemas do Manyôshû acham-se classificados quanto às suas temáticas em: banka, sômon e zôka.

Em poucas palavras, os dois primeiros tipos falam excepcionalmente dos relacionamentos humanos: o banka, daqueles sentimentos voltados à morte de alguém e o sômon, dos sentimentos ligados ao viver cotidiano. Os demais assuntos, muitos dos quais relacionados aos eventos da Corte japonesa, estão em princípio, englobados no zôka.

\section{Banka}

Banka é pois, o poema elegíaco por natureza, cuja temática gira em torno da morte de alguém. A designação banka, dada a este tipo de poema no Japão, foi emprestada da literatura chinesa, segundo a qual os poemas entoados pelos puxadores das cordas atadas à carruagem do esquife, durante o seu trajeto à tumba, eram assim conhecidos.

Segundo Os banka do Manyôshû do pesquisador Kume Tsunetami, a primeira tentativa japonesa de explicar este termo banka é feita pelo monge 
Keichû. na obra Manyô Daishôki, concluído em 1690. Keichû, valendo-se das definiçōes do banka encontradas nas obras chinesas explica:

"Em Gyokuhen (Dicionário de ideogramas chineses), organizado em 543, na dinastia Liang, consta: Ban é conduzir para longe o morto. Equivale a puxar."

"Em Li-chi, um dos cinco livros do Confucionismo que fala dos preceitos éticos, parte 3, cap. Dangu, pag. 135, consta: Aquele que participar da cerimônia fúnebre deverá segurar o cordão que puxa a carruagem fúnebre, $e$ se acompanhar o féretro ao túmulo, deverá ajudar na descida do caixão à cova."

"Em Sôshinki, novelas fantásticas , escritas por Kanpô, na dinastia Shin (séc. III ao V) da China, consta: Banka é a música da família enlutada. Aquele que ajuda no transporte da carruagem fúnebre, puxando a corda desta, deve também acompanhar na sua música."

Constatamos de nossa parte que, no cap. 16, item 177. pag. 193, da mesma obra, ainda relacionado à questão, o autor explica: "banka é a música da cerimônia fúnebre. É o canto entoado pelos que puxam o cordāo do féretro; há dois tipos de poemas que são entoados no caso: o Kairo e o Kôri e os dois são de autoria dos discípulos de Denwô"

Denwô tornou-se chefe da província de Sai no séc. Il aC., mas não resistindo às pressōes do primeiro imperador da dinastia Han, que o sucedera, suicidou-se. Entoando os cantos de Kairo cujo teor é lamentaçōes da fugacidade da vida que se desfaz feito orvalho das folhas de Onira (a scallion) e o kôri, onde consideram a morte como o retorno da alma ao monte Kôri, espaço sagrado ao sul de Taisan, os súditos de Denwô lamentaram a sua morte.

Consta ainda na citação de Keichû: "Nas notas de Li Shû Kan em Wen-hsuan (Coletâneas de obras selecionadas das dinastias Shû, séc. XVII aC. da China) diz: "Denwô suicidou-se; seus seguidores não conseguem chorar e não vencendo a tristeza, elaboram um poema elegíaco onde expōem os seus sentimentos. ... Posteriormente foram elaborados os cantos do tipo Kairo e Kôri, para serem entoados nos acompanhamentos funerais dos mortos. ... Na época de Li En nen (séc. II), Kairo é o poema entoado para os soberanos e os seus familiares e Kôri para os nobres dignatários e o povo em geral, por aqueles que puxam o féretro, de onde estes poemas ficaram conhecidos como banka."

Segundo Keichû e seguido pelos demais pesquisadores japoneses, banka é o canto entoado pelos que acompanham o féretro durante o ceri- 
monial do enterro, costume, observado na antiga China. Não há porém na história do Japão o mesmo costume registrado na China. No entanto, os poemas elegíacos japonses do Manyôshû foram classificados como banka, seguindo os moldes chineses.

A antologia registra 53 banka, elaborados na forma chôka (poema longo) e 184 na forma tanka (poema curto de 31 silabas), num total de 237.

A relação dos poemas de temática banka do Manyoshû é:

vol. 2-94; vol. 3-65; vol. 5-4; vol. 7-13; vol. 9-17; vol. 13-24; vol. 14-1; vol. 15-4; vol. 16-10; vol. 17-1; vol. 19-3; vol. 20-1.

Os volumes 2, 3, 7, 9, 13 e 14 apresentam divisões temáticas em seus volumes e os banka contam com um espaço próprio. Os banka dos demais volumes: 5, 15, 16, 17 e 20, não estão enquadrados como tal mas apresentam caracteristias de banka.

Segundo Morimoto Harukichi em $O$ artístico no Manyôshû, o número de poemas que falam da morte aumenta consideravelmente a partir da antologia Manyôshû em se comparando com os poemas do Kojiki ou Nihon shoki, crônicas históricas do séc. VIII. Morimoto considera que numa sociedade primitiva, a morte estava relacionada à mitologia e, portanto ao sacro, não podendo ser considerada assunto literário. No Manyôshû, a morte, já como realidade cotidiana, palpável e sentida, haveria portanto a possibilidade de tratá-la objetivamente na produção literária. Para que a morte se torne objeto literário há necessidade de um distanciamento entre o homem que produz a obra e a morte em sí. É necessário esperar a formação de uma visão mais fria e desapaixonada para encarar a morte e o ser que a chora. Por isso os japoneses qualificam o banka como "a fala elegante da tristeza"

Segundo Kume Tsunetami (op. cit.), o prof. Takeuchi Kinjirô, em Bankaron (tratado sobre o banka), classifica os banka do Manyôshû em: - banka que 0 autor fala da sua própria morte, como poema de despedida deste mundo; os que falam da morte dos outros; os que consolam os relacionados ao falecido; os que discorrem sobre o falecido, ou até de personagem lendários, e por final poemas que falam da morte de alguém da família imperial.

Iwashita Hitoshi em Sôsôno Minzoku (Raça e costumes funerários), diz: a morte para o antigo povo japonês, significava o afastamento da alma de seu corpo, partindo para os espaços de Yomi (a fonte amarela, a terra dos mortos); quando acontece desta alma retornar ao corpo, é dito yomigaeru (Retorno de Yomi). Na expectativa deste retorno, o morto era depositado no Tamadoko (Leito da alma), onde eram feitas as tentativas do seu retorno mediante rezas, cantos e danças e onde eram requisitados poemas do tipo 
banka. O poema no 207 do vol. 2 de autoria do poeta Kakinomotono Hitomaro, relata a procura do poeta, no encalço da alma de sua esposa, virtualmente morta. Este periodo de espera é denominado araki ou mogari. Para os soberanos falecidos eram construídos recintos especiais de tamadoko, onde além de rituais religiosos, eram declamados os banka (ex: banka 199 vol. 2, do poeta Kakinomotono Hitomaro, dedicado ao príncipe Takechi, falecido em 696. Nestes recintos conhecidos como arakinomiya ou mogarinomiya eram também lidos os shinubigoto, palavras de condolências e louvores ao falecido.

Não havendo esperança de retorno da alma ao seu corpo, realizava-se o enterro. $O$ poema $n^{\circ} 460$ do vol. 3 , da poetiza Sakanoueno Iratsume, fala do enterro da monja coreana Rigan, vinda de Sila que falecera em sua casa. Segundo o poema, o corpo da falecida é levado para bem longe, provavelmente à montanha.

O termos haburu, enterrar, tem a mesma raiz de haburu, jogar ou de haburu, soltar, todos redigidos em ideogramas diferentes. Além do enterro em covas (dosô), havia o costume de cremação (kasô) e o ato de espalhar as cinzas ao vento ou abandonar ao relento o cadáver (fûsô). O poema 1405 do vol. 7, cita o fûsô. Desta feita, mediante os banka do Manyôshû pode-se chegar a um estudo dos costumes antigos inclusive aos relativos à morte.

\section{Sômon}

Kamimura Etsuko alega que a leitura dos ideogramas chineses utilizados para a transcrição desta classificação foi fixada a partir dos estudos de Inoue Michiyasu, que decidiu pela de Sômon, ao constatar que na era da antologia em questão prevalecia a leitura à moda chinesa dos ideogramas no Japão. A despeito de esta leitura ter se fixado entre os pesquisadores do Manyôshû, há registros de outras maneiras de leituras, no decorrer do tempo, como observa Kamimura:

$\begin{array}{lcll}\text { Nome da obra } & \text { Data } & \text { Autor } & \text { Leitura } \\ \text { Manyô Shûishô } & 1690 & \text { Kimura Kigin } & \text { Aikikasuru uta } \\ \text { Manyô Dômôshô } & 1725 & \text { Kada Nobuna } & \text { Aikiki } \\ \text { Manyô. Kô } & 1785 & \text { Kamono Mabuchi } & \text { Aikikoe } \\ \text { Manyô Hinotsumade } & 1828 & \text { Kishimoto Yzuru } & \text { Aikikoe } \\ \text { Manyôshu Koji } & 1848 & \text { Tachibana Moribe } & \text { Aigikoe } \\ \text { Manyô Kogi } & 1890 & \text { Kamochi Masazumi } & \text { Shitashimi uta }\end{array}$

\section{Sobre o significado de Sômon}

Segundo levantamento feito pela mesma pesquisadora Kamimura, sāo vários os pesquisadores que abordam a questão: 
1. Sengaku, em Manyôshû Chûshaku, de 1269:

Sômon é o poema do encantamento amoroso, apesar de registrar também poemas de desencanto amoroso. Em sua maioria são poemas em que o poeta está com os pensamentos fixos em alguém.

2. Keichû, em Manyô Daishôki, de 1687:

Sômon é o poema que na segunda antologia poética japonesa Kokin Wakashû aparece sob a classificação de koiuta (poemas de amor). O koiuta trata unicamente do relacionamento entre o homem e a mulher, enquanto o poema tipo sômon do Manyôshû engloba aquele que fala de parentes e amigos além dos ditos poemas de amor. Sômon significa "diálogo" Apesar dos sômon do Mianyôshû terem seus destinatários expressos, isto não implicava em que a obra chegasse às mãos do interessado, pois os poemas desta antologia já se constituiam como apenas a expressão da individualidade.

3. Kishimoto Yuzuru, em Manyôshû Kôshô, de 1828:

São poemas em que os poetas relatam seus sentimentos provocados por uma 3 $3^{\text {a }}$ pessoa. Trata dos relacionamentos entre seres humanos mesmo que não haja registro de uma resposta. Em Wen-hsuan ou Monzen como é conhecido em japonês, obra chinesa já citada, na carta do poeta Sô Shi Ken enviada ao colega Go Ki Ju encontram-se os termos: "... não sendo possivel uma comunicação oral trocaremos mensagens (utilizando para este termo o ideograma sômon), com certa frequência..." Na obra não se observa este tipo de classificação de poemas e o termo sômon é utilizado no sentido de correspondência epistolar e não fica restrito aos poemas de amor.

4. Yamada Yoshio em Sômon Kô, faz um levantamento das obras chinesas em que aparece o termo sômon e a partir desses dados, enumera alguns significados do sômon como: relacionamento humano, comunicação, visitas, cartas e conclui: de um modo geral, sômon é a comunicação entre pessoas, indagando e respondendo assuntos de seus interesses. $O$ ideograma sô significa mutualidade, reciprodade e mon é ouvir.

Os demais pesquisadores seguem cada qual as idéias expostas pelos que os precederam neste assunto. Dentro da antologia poética Manyôshû, o termo sômon serve para classificar os poemas cuja temática fala da preocupação ou implicação de um ser humano para com o seu semelhante vivo pois, em se tratando do morto, o poema seria considerado um banka.

Quanto ao número de poemas do tipo sômon, que se acham compilados no Manyôshû, Kamimura Etsuko, no artigo já mencionado, calcula 1733, dos quais 47 estão na forma chôka (poema longo); Itô Haku em Manyô Sômon no Sekai (O mundo do sômon no Manyôshû), soma 1751 sômon; Sasaki Yukitsuna em Sômon, acha que o número de poemas do tipo sômon na antologia ultrapassa 1700 . Estas diversidades nas contagens dos poemas 
resultam daqueles que não estão reunidos sob o título de sômon mas apresentam caracteristicas deste tipo.

Dentre aqueles rotulados como poemas de amor, há os que falam do bem querer, da tristeza de uma separação, de respeito e admiração ou mesmo de uma atração quase-amor por alguém e aqueles que se martirizam por ciúmes. É evidente que, sem uma nota explicativa, geralmente anteposta ao poema explicitando o motivo e o relacionamento que se estabelece entre o autor e o seu interlocutor em termos de: da mãe para o filho ou filha, entre amigos, entre irmãos, imperadores e damas da corte, etc., muitos destes poemas, principalmente aqueles tanka (poema curto), não difeririam em nada dos koiuta (poema de amor), das antologias de épocas posteriores.

O Manyôshû insere poemas que se configuram como romances palacianos, envolvendo nomes de imperadores e príncipes. A despeito de seu teor romântico a maioria deles não se acha enquadrada no tipo sômon e sim, considerada zôka. É o caso dos poemas 20, 21 e 23 do vol. 1, cujos protagonistas são o imperador Tenji e seu irmão e sucessor imperador Tenmu, que trocam juras de amor com a dama da corte Nukatano ôkimi. Assim é também o grupo 107, 108, 109 e 110 do vol. 2 da antologia, cujos autores são os príncipes Otsu e Kusakabe num triângulo amoroso com a dama Ishikawano iratsume.

O volume 15 do Manyôshû registra 63 poemas (de n- 3723 a 3785) do tipo sômon, de autoria de Nakatomino Yakamori e sua amada Sanono Chigamino otome. Ela pertence à classe das Joju, donzela ofertada pelo chefe de província para os serviçais da corte e considerada propriedade do imperador, sendo-lhe proibida qualquer ligação amorosa. Casando-se clandestimamente com Yakamori, são punidos quando descobertos e Yakamori é desterrado para Echizen, atual provincia de Ishikawa. Desta separação imposta, resultou essa série de poemas que enriquece hoje a literatura japonesa.

Nos estudos dos poemas populares, classificados como sômon e incluídos nos volumes 11, 12, 13 e 14 do Manyôshû, frequentemente são trazidas em termos de comparação, as cançōes primitivas inseridas nas obras Kojiki ou Nihonshoki, já citadas. De fato, os poemas destes volumes se identificam com aqueles, qualificados como utagaki (cançōes de amor), que retratam os costumes da vida campesina da antiguidade japonesa, em que se relacionavam a idéia de fecundação e produção ao ato sexual. Os poemas refletem os rituais e preces desejando ou agradecendo a boa safra e os festins licenciosos, de comes e bebes, danças, cantos e encontros amorosos. Toda a produção da terra emanava de uma força mágica e, nesse sentido, a mulher e a terra se identificavam na procriação e na magia. Os cantos entoados - utagaki - se caracterizavam primordialmente, pela inovação à elevação da produtividade e mais tarde tendem para a expressão única do prazer. $\mathrm{O}$ ato sexual era envolto pela magia divina e era então de caráter socializante. 
Essas considerações à parte, muitos dos sômon levam nas suas expressōes, palavras tidas com certos poderes de magia, utilizadas comumente nos atos divinatórios, e aproveitadas pelos poetas, num desejo de concretização dos seus amores. Assim, os entroncamentos das vias, as portas eram os lugares prediletos dos espiritos e onde eram esperadas as revelações. A sorte era detectada pelo interessado nos gestos ou nos trechos das falas das pessoas que, por acaso ai transitavam. O horário propício era o entardecer, quando a ação dos espíritos tornavam-se mais evidentes. Têm significdos especiais também nos poemas do tipo sômon, o atar o laço, conotando a idéia de união; a troca de peças intimas da vestimenta entre os amantes; os gestos de acenar com as mangas; o tropeçar do cavalo, sinal de apêgo por alguém que ficara para trás; o desatar da faixa como aceitação incondicional entre amantes; o travesseiro, o pente, o espelho, o sonho eram termos que aparecem com certa frequência nos poemas amorosos.

O sômon do Manyôshû estão agrupados em subcategorias, que foram estabelecidas pelos organizadores. Estão eles deta feita subdivididos em: hiyuka (poemas com metáforas), seijutsu shinto (linguagem direta), kibutsu chinshi (comparação) e mondô uta (troca de comunicação).

No Hiyuka, o poeta serve-se da forma indireta para a sua expressão. $O$ poeta, no caso se expressa por metáfora.

Ex.: poema 392, vol. 3 "Nubatamano sono yono umeo tawasurete orazu kinikeri omoishimonoo"

"Deixei de colher a flor de ameixeira dessa noite. Flor que ficou na recordação"

O poeta fala da flor, mas um outro sentido latente se aflora, substituindo-se a flor pela figura da jovem. $O$ que de fato o autor lamenta é não ter conquistado a jovem.

O Manyôshû insere 164 poemas do tipo hiyuka distribuídos em: vol. 325; vol. 7-108; vol. 10-3; vol. 11-13; vol.13-1; vol. 14-14.

Seijitsu shinto \&̇ uma ouitra subdivisão do sômon. A abordagem dos sentimentos neste tipo de poema é direta, sem subterfúgios nem mediaçōes.

Ex: poema no 2864, vol. 12

"Waga sekoo imaka imakato machioruni yono fukenureba nagekitsurukamo" "Na ansiedade de revê-lo minuto a minuto, a noite se faz alta. Só fica o lamento."

O volume 11 do Manyôshû, registra 47 poemas do tipo seijutsu shinto transcrito do Hitomarokashû (coletânea do poeta Hitomaro) e mais 102 
poemas sem registro de suas procedências. $O$ volume 12 insere 10 transcritos também do mesmo Hitomarokashû e outros 100 de procedência ignorada. No total são 259 poemas do tipo seijitsu shinto, incluídos no Manyôshû e todos na forma tanka, poema curto de 31 sílabas.

Kibutsu chinshi é outra subcategoria do sômon da antologia. No caso o poeta vale-se da técnica da compraração para a abordagem dos seus sentimentos. E a comparação se faz por meio da técnica do jokotoba, frequentemente vista nos poemas do tipo tanka. $O$ tanka é composto de 5 versos com a seguinte métrica: 5 silabas, 7 silabas, 5 silabas, 7 silabas e 7 sílabas. O poeta utiliza, no caso os 3 primeiros versos (5-7-5 sílabas), para criar uma imagem que servirá de inrodução a um termo que só aparecerá no segundo segmento (7-7), do poema. Os primeiros 3 versos serão denominados jokotoba.

Ex: Poema 2449, vol. 11. "Kaguyamani kumoi tanabiki ôhoshiku
aimishi korao nochikoimukamo"
"Nuvens que pairam no monte Kagu
do desencontro fugaz e os sentimentos que
ficam"

Os sentimentos acham-se comparados às nuvens na montanha. Sentimentos que ficaram para com a moça, de um desencontro fugaz.

A antologia registra 428 poemas classificados como do tipo Kibutsu chinshi, 280 no volume 11 e 148 no volume 12.

O Manyôshû registra também alguns poemas da temática sômon, classsificando-os pelo tipo de abordagem em mondô, que literalmente significa "pergunta e resposta"

São eles: 27 no vol. 11; 26 no vol. 12; 17 no vol. 10 e 4 no vol. 7. Dentre estes 2 do vol. 10 e os 4 do vol. 7 não são da temática sômon e sim, classificados como zôka. Além destes, encontramos nos volumes 4 e 14 alguns poemas que constituem correspondência entre pessoas, mas que não foram catalogados como tal. O mais conhecido poema do tipo mondô é de autoria do poeta Yamanoueno Okura que elabora um chôka - poema longo (poema no 892 do vol. 5), composto de duas partes, formando um diálogo travado entre dois chefes de família, que retratam a situação de extrema miséria vivida pelos lavradores da época.

\section{Zôka}

A terceira classificação temática dos poemas do Manyôshû a ser apresentada é o zôka. 
Omodaka Hisataka em sua obra Manyôshû Chûshaku, diz que o termo zôka fôra tomado emprestado da coletânea chinesa Monzen (Wen-hsuan).

Itô Haku em Manyôshû zôkano tenkyoo megutte (Observações sobre as fontes do zôka do Manyôshû), diz: "... o termo zôka adotado para uma classificação temática dos poemas do Manyôshû, fora emprestado da coletânea Monzen, embora o zôka japonês seja mais abrangente, diferindo um tanto dos assim classificados poemas chineses."

Em Monzen, consta que Zasshi ou zatsugi ou zakka (com o mesmo significado do ideograma do zôka) são poemas sem título ou mesmo com títulos, que não se enquadram nas suas demais temáticas. Ainda em Monzen, p. 669, diz: “... zatsu significa que não é só de um tipo e gi é comparar ou igualar a. Como explica o poeta Ryûrô, reuniram-se sob esta denominação os poemas que apresentam certas analogias temáticas ou formais com os poemas antigos da China, compostos deliberadamente numa firme tentativa de imitar os antigos."

À p. 548, Monzen ressalta: “... o zakka são poemas antigos do Gafu. Incluem-se nesta categoria, também, os poemas modernos que são imitaçōes do Gafu.

Na p. 469 diz: "Gafu é o nome da repartição pública chinesa, criada na era do imperador $\mathrm{Bu}$, da dinastia Han (séc. II), onde eram feitos os trabalhos de compilação de toda a produção de poemas do país, os quais eram ali musicados e divulgados para serem cantados. Estes poemas cantados eram denominados gakuka, mais tarde conhecidos como gakufu, posteriormente abreviados em gafu. São poemas de métricas irregulares. Os poemas produzidos após a dinastia Han, que tomaram como seus modelos o gafu foram incluídos nesta categoria. O Monzen insere poemas da dinastia Wei (220-265) e da dinastia Tin (265-280), enquadrados no gafu"

Como constata Itô Haku, o zakka em Monzen seria "poemas de métricas variadas" e no Manyôshû, uma classificação que engloba todos os poemas que não se enquadram nas temáticas sômon e banka.

No Japão, entre os pesquisadores é corrente a leitura zôka ou mesmc kusagusano uta, para a nomenclatura desta temática, apesar de ainda ter pessoas como a pesquisadora Miyazaki Harumi que opta pela leitura chinesa em zakka, conforme se lê em seu artigo Manyôshûno zakka.

Quanto aos estudos do significado de zôka no Manyôshû, têm destaques os seguintes trabalhos:

1. Monge Keichû em Daishô Sôshaku, p. 23: zôka é o pomea do tipo zôno uta, visto nas antologias posteriores ao Manyôshû organizadas mediante decreto Imperial (Chokusenshû). 
Para esclarecimento, o zôno uta do Kokin Wakashû, chokusenshû concluído em 905, agrupa os poemas que não se enquadram no grupo dos koino uta (poemas de amor).

2. Kadano Azumamaro em Dômôshô, interpreta o zôka como poemas que não se identificam com os sômon e divagam sobre assuntos variados.

3. Kamono Mabuchi em Manyôkô considera: zôka são poemas de variados assuntos como aqueles que falam de viagens em geral ou das viagens empreendidas pela comitiva imperial e poemas que falam dos cerimoniais e dos festejos palacianos.

4. Kamochi Masazumi em Manyôkô Kogi Sôron, diz: São poemas de variados assuntos. É mais abrangente que os classificados em zôno bu (poemas variados) das antologias poéticas posteriores ao Manyôshû. Inserem nos zôka do Manyôshû os poemas que falam de viagens, principalmente aques que dizem respeito às viagens organizadas pela corte imperial, os que falam dos festejos palacianos, os poemas ditos "diálogos poéticos" e outros. Incluem-se nesta classificação os poemas que não cabem no tipo sômon e banka.

Esta definição de zôka traçada por Kamochi Masazmi é atualmente a mais aceita pelos pesquisadores japoneses. Em linhas gerais, excluindo-se as temáticas enquadradas no banka e sômon, os demais assuntos abordados nos poemas do Manyôshû são classificados como zôka. Cumpre, acrescentar que, apesar da amplitude de temas possiveis no zôka, a maioria deste está relacionada com os acontecimentos centrados na corte, de onde vem a idéia de zôka como sendo poemas de caráter ofcial em contraposição ao sômon e banka, que são de assuntos particulares.

De acordo com Tsujoji Shin'ichi em Zôka, in Manyôshû Kôza, os poemas do tipo zôka, estão distribuídos nos seguintes volumes da antologia I vol. 1,5 e 6, compostos somente de zôka; vol. 3 e 7, contendo zôka, hiyuka e banka; vol. 9, contendo zôka, sômon e banka; vol. 13, com zôka, sômon, mondô, hiyuka e banka; vol. 14, com zôka, hiyuka, sakimorino uta (poemas dos expedicionários da região norte do país que eram escalados para servir nas fronteiras do sul, na época), e banka; vol. 8 e 10, contendo poemas sobre as quatro estaçōes do ano, subdivididos nas temáticas zôka e sômon; vol. 16, contendo zôka, que cantam as lendas e tradiçōes.

A distribuição dos zôka nestes volumes seguem a listagem seguinte:

\begin{tabular}{l|rrrrrrrrrrr|r}
\hline Forma do poema & \multicolumn{11}{|c|}{ Volumes } & Total \\
\hline & 1 & 5 & 6 & 3 & 7 & 9 & 13 & 14 & 8 & 10 & 16 & \\
Chóka & 16 & 10 & 27 & 14 & 0 & 12 & 16 & 0 & 3 & 3 & 8 & 109 \\
Tanka & 68 & 104 & 132 & 141 & 204 & 89 & 10 & 22 & 171 & 532 & 92 & 1412 \\
Sedóka & 0 & 0 & 1 & 0 & 25 & 1 & 1 & 0 & 3 & 2 & 3 & 36 \\
Bussokusekika & 0 & 0 & 0 & 0 & 0 & 0 & 0 & 0 & 0 & 0 & 1 & 1 \\
\hline
\end{tabular}


Segundo este levantamento de Tsunoji Shin'ichi o tanka é a forma poética mais procurada pelos poetas na elaboração dos zôka, seguido da forma chôka. O sedôka (poema de seis versos, de 5-7-7 sílabas, repetidas duas vezes), com menos produção e bussokusekika (poema composto de 57-5-7-7-7 sílabas), com um único exemplar em toda a antologia e que é classificado como ¿ôka.

Acrescentamos que, pelo levantamento feito por nós, além destes, constatamos mais 14 chôka (poema longo, na métrica 5-7-5-7-7-7 ... 7 sílabas), no volume 19 e 3 também da forma chôka no volume 20 , que poderiam ser enquadrados no zôka.

Analisando um pouco mais detalhadamente o tipo zôka do Manyôshû, verificamos que 0 assunto que maior número de incidências apresenta é aquele que fala das estações do ano e que estão inseridos nos volumes 8 e 10.

A divisão dos poemas em quatro estações já é vista na antologia chinesa Gyokudai Shin'ei (conforme leitura japonesa), de 10 volumes, organizada por Joryô da dinastia Chin, extinta em 479 aC., onde presume-se que se inspiraram os organizadores do Manyôshû, na composição destes seus dois volumes. Esta organização é adotada também nos chokusenshû japoneses de épocas posteriores.

Os poemas do tipo zôka, das quatro estaçōes, naturalmente falam da natureza e dão destaques ao céu, à lua, às nuvens, à chuva, às montanhas, às colinas, aos rios, ao orvalho, ao pássaro, à flor, à folhagem, à fonte, à terra natal. Os lugares mais abordados são Yoshino, Yamashiro e Settsu.

Segundo Ishii Shôji em Manyôshû Kôsetsu (Inquirição sobre o Manyôshû), citado em Manyôshû Taisei os assuntos preferencialmente abordados em cada estação do ano, na antologia são: - na primavera os mais explorados são: a ameixeira, a cerejeira, a neblina, a neve, o rouxinol e o chorão; no verão vem o cuco e o citrus; no outono, a lenda do Tanabata, as folhas secas, as flores de hagui (lespedeza bicolor), o orvalho, o pato selvagem, a corça e no inverno é a neve.

Tanabata é uma lenda de origem chinesa, em que se festeja o encontro das estrelas Vega e Altair, que ocorre anualmente na noite de 7 de julho. Conta a lenda que as estrelas Vega, a tecelã, e Altair, o pastor, vivem separadas pela Via Láctea por imposição da divindade celeste por terem cada qual descuidado de seus afazeres, perdidos que estavam em amores um pelo outro. Foi-lhes concedido apenas um encontro anual na noite de 7 de julho, quando as aves kasașagi (a magpie) estendem as asas possibilitando à estrela Vega a travessia da Via Láctea. Segundo Shoku Nihongi, compilado em 797, este costume no Japão vem desde a noite de 7 de julho de 734, quando o então imperador Shômu (724-749), após assistir a um tomeio de 
sumô (luta japonesa), já ao entardecer, ordena aos letrados reunidos a composição de poemas longos, sob o título Tanabata.

São 132 poemas do Manyôshû, incluídos nos volumes 8, 9, 10, 15 e 17 que tratam do tanabata e que são considerados do tipo zôka.

O zôka comporta também aqueles poemas que falam das viagens. A maioria destas viagens era realizada pela corte imperial. A comitiva era geralmente acompanhada pelos poetas, hoje consagrados poetas da corte, que cantavam as estâncias escolhidas pelo imperador, incutindo em seus poemas um toque político, enaltecendo sempre a magnanimidade dos seus imperadores, representando desta feita os anseios de uma coletividade para com aquele que centralizava em sua mãos o poder na época.

Ainda relacionados aos temas de viagens dentro do zôka, encontramse 19 poemas dedicados aos emissários que partem para Tang ou para Sila em missōes do governo.

Estão inseridos entre os zôka, mais de 200 poemas que falam dos festejos organizados pela corte ou membros da nobreza de então. $O$ volume 5 do Manyôshû registra poemas que apreciam as flores de ameixeira, elaborados por 32 altos funcionários do governo, por ocasião de uma reunião poética realizada pelo nobre Otomono Tabito, em sua residência. Segundo notas antepostas ao poema $n^{\circ} 4229$, do vol. 19, em janeiro de 751 , o poeta Yakamochi, então na chefia da província de Inaba (hoje Tottori), organiza reuniōes nesse mesmo estilo.

O volume 18 do Manyôshû registra 12 poemas, datados de março, primavera de 748, elaborados pelos poetas reunidos na residência do mesmo Yakamochi, já como chefe da província de Echizen (atual Ishikawa) homenageando o poeta Tanabeno Sakimaro que teria sido enviado à sua pronúncia pelo primeiro ministro Tachibana Moroe.

Outros tipos de reuniōes literárias e festas eram comumente realizadas como registram as notas explicativas dos poemas inseridos no zôka dos volumes 17 e 18 do Manyôshû. Reuniōes musicais com apresentação de poemas estão presentes também nos volumes 6 e 16. O volume 3 registra 13 poemas de elogios ao sake (bebida), de autoria de Otomono Tabito, numa licenciosidde que supera os preceitos éticos do Confucionismo, Taoísmo e Budismo, imprimindo o seu escárnio àqueles que se portam como inimigos da bebida.

Merecem destaque os poemas elaborados para as reuniōes festivas - ritsuen - onde os encômios ao imperador davam o toque solene. Zôka do tipo ôshô (apresentação de poemas feita por solicitação nessas cerimônias de caráter oficial), são encontrados na antologia. $O$ volume 17 registra 5 poemas (3922-3926), com uma nota de que os demais se extraviaram, 
de uma reuniāo realizada em $1^{\circ}$ de janeiro de 746 na residência da imperatriz já abdicada Genshô (715-724), com a presença de 23 exímios poetas, liderados por Tachibana Moroe.

O volume 19 registra o ritsuen, realizado em 25 de novembro de 752 , comemorando a primeira colheita anual do arroz (Niiname) apresentando 6 poemas do tipo zôka, com as características de ôshô.

Os poemas que louvam as antigas capitais, em número de 40 no Manyôshû, também estão classificados no zôka. Sabe-se que na antiguidade japonesa era de costume a transferência da sede do governo nas trocas de imperadores. O chôka (poema longo), no 29 do vol. 1, de autoria do poeta Kakinomotono Hitomaro, canta todo o processo histórico da mudança da capital de Asuka para Omi, empreendida pelo então príncipe Nakano Ôe, relatando com nostalgia os dias de glórias e o seu estado de abandono da então capital Omi, que o poeta consegue expressar com rara sensibilidade.

Os poemas que falam das lendas também estão classificados como zôka. No volume 3 temos 3 poemas (385-387), de autoria de Wakamiyano Ayumaro que canta a lenda de Yamabino Tsuminoe. É a lenda do pescador de nome Umashine, residente da província de Yoshino, que numa de suas pescarias resgata um ramo de amoreira que descia o rio e este se transforma em uma fada. Na coletânea de poemas escritos em estilo chinês, Kaifûsô, também do sec. VIII, há inúmeros poemas que fazem menção a esta lenda de Yoshino, reforçando o caráter fantástico dessa paragem, nos moldes daquele vistos nos poemas chineses.

O volume 16 registra uma série de poemas classificados em Zôka, do tipo Yue Yoshiaru uta (poemas fundamentados em fatos antigos), que também tratam de coisas lendárias do país. $O$ volume insere inclusive zôka de tendências cômicas.

No volume 9 aparece o chôka que narra a lenda de Urashima. Esta lenda é vista no ivihonshoki, no capítulo que fala do imperador Yûryaku (da pré-história japonesa), ou no Fudoki da província de Tanba, hoje sob jurisdição de Kyoto. Fudoki é levantamento sócio geográfico, organizado por decreto da imperatriz Genmei, em 713. O poema no 1740 cita a localidade de Naniwa, atual Osaka, como ponto referencial de fonte da lenda. A lenda em si trata da história de um pescador de nome Urashima Tarô que viveu momentos fantásticos no fundo do mar, em companhia de uma princesa divina, como recompensa por ter salvo a um tartanuga. Tomado pelas saudade, Tarô retorna à terra, quando a realidade cruel e brusca, se revela na transfiguração de sua figura de jovem pescador para o de anciāo e o faz conscientizar do tempo decorrido em seu devaneio.

Os poemas que falam dos problemas sociais ou existenciais em número que não ultrapassam de 60 , também estão classificados como zôka. 
Os poetas que abordaram estes assuntos foram poucos e podemos citar os nomes de Yamanoueno Okura e Otomono Yakamochi e as obras que mais se destacam dentro destas temáticas são: - sobre as dificuldades de sobrevivência: poema 892, vol. 5 do poeta Okura; - conselhos éticos para os jovens: poema 800 , vol. 5 , de Okura e o poema 4106, vol. 18, de Yakamochi. - Sobre doença e velhice: poema 897, vol. 5, de Okura e os poemas 3962 a 3969 do vol 17 e 4468 do vol. 20 igualmente de Yakamochi. - Sobre os fiIhos: poemas 802, 803 e 904 do ol. 5, de Okura. - Sobre a fugacidade da vida: poemas 804 do vol. 5 e 978 do vol. 6, ambos de autoria de Okura e os poemas 4160 a 4470 do vol. 19 de Yakamochi. Além destas temáticas temos os poemas $4311,4408,4398$ inseridos no volume 20 , do poeta Yakamochi que falam da vida dos sakimori. Sakimori eram os lavradores recrutados no nordeste do país para os serviços de guardas de fronteiras nas ilhas do sul do Japão.

Apresentamos em linhas gerais as três grandes divisões temáticas nas quais estão classificados, em princípio, os mais de 4500 poemas da antologia Manyôshû e rápidas pinceladas nos diversificados assuntos abordados pelos poetas japoneses da antiguidade. Anexamos ainda as subdivisōes dos poemas do tipo sômon, que foram estabelecidas levando-se em conta a técnica de expressão na composição destes. Nota-se hoje que, desde então, não houve muitas modificaçōes nas técnicas e temáticas dos poemas japoneses, principalmente em se tratando de seus Tanka, permanecendo ainda estas heranças dos séculos VIII, vivas em suas produçōes poéticas.

\section{Bibliografia:}

ITÔ, Haku, Manyôshû zôkano tenkyoo megutte (Observaçōes sobre as fontes do zôka no Manyôshû), in periódico Manyô, Tóquio, ed. Manyôshû Gakkai, 1, out., p. 1-8. 1951.

IWASHITA, Hitoshi, Sôsôno minzoku (Raça e costumes funerários), in Manyôshû Hikkei, n 3, Tóquio, Gakutôsha, p. 62, 1979.

KAMIMURA, Etsuko, Manyôshûno sômonka (os poemas do tipo sômon da antologia Manyô), in Manyôshû Taisei, vol. 7, p. 177, Tóquio, ed. Heibonsha, 1954.

KOJIMA, Noriyuki (org.) et alii, Manyôshû Honmon-hen (Manyôshû - texto no original), Tóquio, Hanawa shobô, 1974.

KUME, Tsunetami, Manyôshûno banka (Os banka do Manyôshû), in Manyôshû Taisei, vol. 7, Tóquio, ed. Heibonsha, 1954.

MIYAZAKI, Harumi, Manyôshûno zakka (Os zakka do Manyôshû), in Manyôshû Taisei, vol. 7, Toquio, ed. Heibonsha, 1954.

OMODAKA, Hisataka, Manyôshû Chûshaku (Manyôshû-notas e interpretaçōes), Tóquio, ed. Chûôkôronsha, 1980.

WATASE, Masatada, Manyôshû Jiten (Dicionário do Manyôshû), col Manyôshû Kôza, Tóquio, ed. Yûseidô, 1975. 